University of Nebraska - Lincoln

DigitalCommons@University of Nebraska - Lincoln

Faculty Publications, Department of Psychology

Psychology, Department of

$1-1-2007$

\title{
Acculturative Stress, Social Support, and Coping: Relations to Psychological Adjustment among Mexican American College Students
}

\author{
Lisa J. Crockett \\ University of Nebraska-Lincoln, ecrockett1@unl.edu \\ Maria I. Iturbide \\ University of Nebraska-Lincoln \\ Rosalie A. Torres Stone \\ University of Nebraska-Lincoln, rosalie.torresstone@umassmed.edu \\ Meredith McGinley \\ University of Nebraska-Lincoln \\ Marcela Raffaelli \\ University of Nebraska-Lincoln, mraffaelli1@unl.edu \\ See next page for additional authors \\ Follow this and additional works at: https://digitalcommons.unl.edu/psychfacpub \\ Part of the Psychiatry and Psychology Commons
}

Crockett, Lisa J.; Iturbide, Maria I.; Torres Stone, Rosalie A.; McGinley, Meredith; Raffaelli, Marcela; and Carlo, Gustavo, "Acculturative Stress, Social Support, and Coping: Relations to Psychological Adjustment among Mexican American College Students" (2007). Faculty Publications, Department of Psychology. 299.

https://digitalcommons.unl.edu/psychfacpub/299

This Article is brought to you for free and open access by the Psychology, Department of at DigitalCommons@University of Nebraska - Lincoln. It has been accepted for inclusion in Faculty Publications, Department of Psychology by an authorized administrator of DigitalCommons@University of Nebraska - Lincoln. 


\section{Authors}

Lisa J. Crockett, Maria I. Iturbide, Rosalie A. Torres Stone, Meredith McGinley, Marcela Raffaelli, and Gustavo Carlo 
Published in Cultural Diversity and Ethnic Minority Psychology, 13:4 (2007), pp. 347-355; doi: 10.1037/1099-9809.13.4.347

Copyright (C) 2007 American Psychological Association. Used by permission. "This article may not exactly replicate the final version published in the APA journal. It is not the copy of record." http://www.apa.org/journals/cdp/

\title{
Acculturative Stress, Social Support, and Coping: Relations to Psychological Adjustment among Mexican American College Students
}

\author{
Lisa J. Crockett, Maria I. Iturbide, Rosalie A. Torres Stone, \\ Meredith McGinley, Marcela Raffaelli, and Gustavo Carlo \\ University of Nebraska-Lincoln
}

\begin{abstract}
This study examined the relations between acculturative stress and psychological functioning, as well as the protective role of social support and coping style, in a sample of 148 Mexican American college students (67\% female, 33\% male; mean age $=23.05$ years, $S D=3.33$ ). In bivariate analyses, acculturative stress was associated with higher levels of anxiety and depressive symptoms. Moreover, active coping was associated with better adjustment (lower depression), whereas avoidant coping predicted poorer adjustment (higher levels of depression and anxiety). Tests of interaction effects indicated that parental support and active coping buffered the effects of high acculturative stress on anxiety symptoms and depressive symptoms. In addition, peer support moderated the relation between acculturative stress and anxiety symptoms. Implications for reducing the effects of acculturative stress among Mexican American college students are discussed.
\end{abstract}

Keywords: acculturative stress, social support, coping, Mexican American college students, psychological distress

The Latino population is growing rapidly, and it is estimated that by 2050 , nearly one quarter of the U.S. population will be Latino (U.S. Department of Health \& Human Services, 2001). The number of Latino students on college campuses has also increased rapidly, from 867,000 in 1991 to 1.4 million in 2001 (American Council on Education, 2005; Wilds \& Wilson, 1998), an increase of $75 \%$. However, graduation rates have not kept pace, suggesting problems with retention and completion (Fry, 2002). Because the number of Latino college students is expected to continue growing, research is needed on factors contributing to the adjustment and academic achievement of these students.

One factor potentially affecting Latino graduation rates is psychological stress. Stress and the psychological distress it engenders may impair students' academic performance (Alva \& de Los Reyes, 1999), resulting in higher dropout rates. A meta-analysis revealed that Latino college students experience substantial levels of stress, reporting higher levels of academic, financial, and personal stress than those of Anglo students (Quintana, Vogel, \& Ybarra, 1991). Although much of the stress burden relates to financial problems and insufficient academic preparation, Latino students often experience

Lisa J. Crockett, Maria I. Iturbide, Meredith McGinley, and Gustavo Carlo: Department of Psychology, University of Nebraska-Lincoln; Rosalie A. Torres Stone: Department of Sociology, University of Nebraska-Lincoln; Marcela Raffaelli: Department of Psychology and Institute for Ethnic Studies, University of Nebraska-Lincoln

Data collection was supported by grants to Marcela Raffaelli and Gustavo Carlo from the University of Nebraska-Lincoln's Research Council, Institute for Ethnic Studies, and Human Rights and Human Diversity Initiative. We thank Scott Roesch and Gabriel Holguien for facilitating data collection. Data analysis and manuscript preparation were supported by Nebraska Tobacco Settlement Biomedical Research Enhancement Funds.

Corresponding author: Lisa J. Crockett, Department of Psychology, University of Nebraska-Lincoln, Lincoln, NE 68588-0308; email: ecrockett1@ unl.edu. acculturative stress (Padilla, Alverez, \& Lindholm, 1986; Rodriguez, Myers, Morris, \& Cardoza, 2000) and stressors related to their minority status (Saldaña, 1994). Despite the likely psychological toll of high stress levels, few studies have examined the stress-adjustment relationship among Latino college students or attempted to identify factors that buffer negative effects of stress. Such research is needed to ameliorate the effects of stress in this growing population. In this study, we focused on acculturative stress and psychological adjustment among Mexican American college students.

\section{Acculturative Stress and Its Effects}

Acculturative stress occurs when individuals experience problems arising from the acculturation process (Williams \& Berry, 1991). It can stem from incongruent cultural values and practices, language difficulties, and discrimination (Gil, Vega, \& Dimas, 1994). Immigrants are most likely to experience this form of stress, but it is also seen in later generations, including later-generation college students (Mena, Padilla, \& Maldonado, 1987; Padilla et al., 1986). Because the children of immigrants acculturate more quickly than their parents, second-generation youth may feel caught between the opposing values of their parents and peers or experience conflict between their own values and those of their less acculturated parents (Miranda, Bilot, Peluso, Berman, \& Van Meek, 2006; Padilla et al., 1986). Such discrepant expectations can create family tension (Szapocznik, Scopetta, Kurtines, \& Aranalda, 1978). The aspects of acculturative stress salient to college students may relate less to English-language proficiency or unfamiliarity with prevailing cultural practices and more to cultural self-consciousness and the experience of conflicting value systems (e.g., Mena et al., 1987). 
Williams and Berry (1991) suggested that acculturative stress leads to negative emotional states such as anxiety and depression. General models of stress posit that perceiving a situation as being threatening or beyond one's coping resources causes stress and leads to negative affect (Barlow, 2002; Cohen \& Wills, 1985; Lazarus $\&$ Folkman, 1984). So, when pressures to assimilate, lack of intercultural competence, or discrimination are perceived as exceeding one's ability to cope, this should lead to a subjective perception of stress and to negative emotions. Several studies have supported an association between acculturative stress and negative affect. For example, acculturative stress has been linked to more depressive symptoms and sometimes to more anxiety symptoms in Latino noncollege populations (Hovey \& King, 1996; Hovey \& Magaña, 2000; Salgado de Snyder, 1987). Studies of acculturative stress in Latino college students are rare; however, in one such study, acculturative stress predicted higher levels of general psychological distress even after controlling for other forms of stress (Rodriguez et al., 2000). Other research indicates that Latino adolescents and adults experience high levels of depressive and anxiety symptoms, often exceeding levels reported by non-Hispanic Whites (e.g., Roberts \& Sobhan, 1992; Torres Stone, Rivera, \& Berdahl, 2004; Varela et al., 2004). Building on this research, we examined symptoms of depression and anxiety among Latino college students to provide a fine-grained analysis of the psychological effects of acculturative stress.

\section{Protective Factors: Social Support and Coping}

A second gap in the literature involves the factors that mitigate the effects of acculturative stress on psychological distress among Latinos. Resilience scholars (e.g., Garmezy, 1994; Masten \& Coatsworth, 1998) have highlighted the importance of identifying protective factors that reduce the negative effect of risk factors and result in positive outcomes. Social support and coping strategies are processes that may help to buffer stress.

\section{Social Support}

Social support, which involves the provision of psychological and material resources, may serve as a buffer against stress by preventing a situation from being appraised as stressful in the first place or by providing a solution to a stressful problem, minimizing its perceived importance, or facilitating healthy behavioral responses (Cohen \& Wills, 1985). Vega, Hough, and Miranda (1985) proposed a model of Latino mental health in which factors such as social support moderate the relations between stress and adjustment. In their model, the effect of stressors depends on the availability of external resources (including social support) and the person's use of coping strategies. Thus, persistent strain (e.g., acculturative stress) is more likely to be associated with elevated symptomatology if social support and internal coping resources are low.

The stress-buffering effects of social support have been documented in past studies of the general population (see Cohen \& Wills, 1985, for a review). However, studies of Latino college students have yielded mixed results. Solberg and Villarreal (1997) found that social support moderated the association between college-related stress and psychological distress such that, consistent with the stress-buffering hypothesis, stress was associated with in- creased distress among students reporting low levels of social support but not among those reporting high social support. In contrast, three other studies with predominantly Latino college samples found no evidence that social support moderated the association between stress and measures of either college adjustment or psychological distress (Alvan, Belgrave, \& Zea, 1996; Rodriguez, Mira, Myers, Monis, \& Cardoza, 2003; Solberg, Valdez, \& Villarreal, 1994). Notably, most of these studies used general or composite measures of social support, and none of them investigated acculturative stress. Thus, the stress-buffering role of social support for Latino college students requires further study.

Social support comes from multiple sources, and different sources may provide different levels and types of support (e.g., Procidano \& Heller, 1983). Latino culture emphasizes familismo, which involves strong feelings of attachment, shared identity, and loyalty among family members (Marín \& Marín, 1991). Latino families are thought to provide emotional support, which protects members against external stressors (Fuligni, Tseng, \& Lam, 1999; Vega, Kolody, Valle, \& Weir, 1991). Consistent with this notion, better family functioning and emotional support from family members have been linked to lower levels of depressive symptoms among Latino adolescents and adults (Hovey \& King, 1996; Vega et al., 1991) and to better emotional adjustment among Latino college students (Schneider \& Ward, 2003). Additionally, peer support may be important for Latino college students. Like parents, friends can provide emotional, informational, and instrumental support; however, they are more likely to be immediately available (on campus) and more likely to have information relevant to negotiating the college environment (Rodriguez et al., 2003). In line with this hypothesis, studies of Latino college students found that emotional support from peers was associated with better social adjustment (Schneider \& Ward, 2003) and that support from friends, but not family, predicted lower psychological distress (Rodriguez et al., 2003). Because support from peers and family may have different effects, we included separate measures of parental and peer support.

\section{Coping Strategies}

In classic stress and coping theory, coping strategies play a critical role in the stress-adjustment relation. Coping includes cognitive or behavioral efforts to manage situations appraised as taxing or exceeding a person's resources (Lazarus \& Folkman, 1984). Thus, coping is a regulatory process that can reduce the negative feelings resulting from stressful events. Generally, active coping (in which the problem is managed cognitively or through action) is thought to mitigate the debilitating effects of stress, whereas avoidant coping (in which the problem is ignored or repressed) is thought to be less effective; empirical research has largely supported these predictions (Compas, Connor-Smith, Saltzman, Thomsen, \& Wadsworth, 2001). Studies of college students have linked active coping methods to better college adjustment in diverse ethnic groups (Zea, Jarama, \& Bianchi, 1995) and to better psychological wellbeing among Latinas (Gloria, Castellanos, \& Orozco, 2005). Furthermore, approach (active) coping predicted lower levels of psychological symptoms in a largely Mexican American sample of inner-city adolescents (Crean, 2004). On the basis of these studies, it is likely that active coping plays a beneficial role in buffering the effects of acculturative stress for Latino college students. In 
contrast, avoidant coping may be ineffective and could even exacerbate the negative effects of acculturative stress.

\section{Gender, Social Support, and Coping}

Associations between social support, coping, and adjustment may vary by gender. Slavin and Rainer (1990) found a negative association between social support and subsequent depressive symptoms that was significantly stronger for girls than boys. In a study of inner-city minority youth, active coping weakened the relation between family stress and conduct problems among girls, consistent with the stress-buffering hypothesis; however, this effect was not significant among boys (Gonzales, Tein, Sandler, \& Friedman, 2001). These findings point to gender differences in the relations among stress, coping, and adjustment. However, to our knowledge, gender differences in the buffering effects of social support and coping strategies have not been studied among Latino college students. We anticipated that the stress-buffering effects of social support and active coping should be stronger for women than for men.

\section{The Present Study}

In this study, we examined the relation between acculturative stress and psychological functioning, as well as the buffering effects of social support and coping. We focused on one subgroup of Latinos (Mexican Americans), because prior research has revealed differences between Latino subgroups on multiple dimensions, including cultural traditions, historical experiences, and demographic characteristics (e.g., Baca Zinn, 1995), as well as depressive symptoms and syndromes (e.g., Crockett, Randall, Shen, Russell, \& Driscoll, 2005). on the basis of theory and empirical research, we predicted that acculturative stress would be associated with higher levels of depressive and anxiety symptoms. Additionally, higher levels of social support from parents and peers and greater use of active coping were expected to reduce the detrimental effects of acculturative stress on psychological functioning, especially for women. Because acculturation level and socioeconomic status have been linked to anxiety or depression in previous studies of Latinos (Cuéllar \& Roberts, 1997; Rogler, Cortes, \& Malgady, 1991), we included measures of these constructs as potential control variables.

\section{Method}

\section{Participants and Procedure}

The study was conducted at three state universities (one in Texas, two in California). Data were collected during the summer in Texas and the academic year in California. The university in Texas had approximately 2,300 students, nearly half of whom were Latino. One of the California universities had approximately 16,000 undergraduate students, about one quarter Latino; the other was larger (25,000 undergraduates) and was less than 20\% Latino. At all three sites, student volunteers from psychology courses provided written informed consent before completing self-report surveys in small groups.

The present analysis was restricted to individuals of Mexican or Mexican American origin or descent. The analytic sample consisted of 148 18-30-year-old students (67\% female; mean age
$=23.05$ years, $S D=3.33)$. Most $(83 \%)$ were born in the United States, but nearly three quarters had one $(26 \%)$ or two (46\%) nonU.S.-born parents.

\section{Measures}

Participants completed a set of standardized measures that have been widely used in previous research and have demonstrated adequate validity and reliability. Descriptive statistics and reliabilities for our sample are displayed in Table 1. Scores for multi-item scales were computed by averaging, and respondents had to provide data on at least $75 \%$ of the items to receive a score. Higher scale scores reflect higher levels of the construct.

Demographic and control variables. Respondents reported their age in years, gender $(0=$ female, $1=$ male $)$, and mother's educational attainment $(1=$ elementary or junior high, $4=$ graduated from a two year school, 7 = professional or graduate degree). Acculturative status was measured with a modified version of the five-item Language Use factor of the Short Acculturation Scale for Hispanics (Marín, Sabogal, Marín, Otero-Sabogal, \& PerezStable, 1987). One item ("In general, what language do you read and speak?") was divided into two, resulting in a six-item measure of linguistic acculturation. Respondents rated the degree to which they used their native language and/or English in different situations on a 5 -point scale $(1=$ native language only, $3=$ both the same, 5 = English only). To control for possible site differences, we created a dummy variable for state $(1=$ Texas, $2=$ California $)$.

Acculturative stress. The Social, Attitudinal, Familial and Environmental Acculturative Stress Scale (Mena et al., 1987) measures stress in four domains: familial (e.g., "Close family members and I have conflicting expectations about my future"), attitudinal (e.g., "I often think about my cultural background"), social ("I don't feel at home"), and environmental ("It bothers me when people pressure me to assimilate"). The 24 items are rated on a scale ranging from 1 (not stressful) to 5 (very stressful).

Parent and peer support. Respondents completed the parent and peer support scales from the Network of Relationships Inventory (Furman \& Buhrmester, 1992). Each 15-item scale assesses five different components of support (companionship, instrumental help, intimacy, affection, and enhancement of worth), with 3 items capturing each component. Statements (e.g., "How often does your parent/friend help you when you need to get something done?") are rated on a 5-point scale ranging from 1 (never) to 5 (always).

Coping. We measured active and avoidant coping using a shortened version of the COPE inventory (Carver, Scheier, \& Weintraub, 1989), which assesses different dimensions of active or avoidant coping styles. Respondents indicated how frequently they used each strategy on a scale from 1 (never) to 5 (always). The subscales were aggregated to form two composite scales: Active Coping (nine items reflecting problem solving, planning, and positive reframing; e.g., "I take direct action to solve the problem") and Avoidant Coping (nine items reflecting behavioral disengagement, mental disengagement/self-distracting, denial, and substance use; e.g., "I just give up trying to reach my goal").

Psychological functioning. The 21-item Beck Anxiety Inventory (Beck \& Steer, 1993) was used to measure anxiety symptoms. Respondents rated how much they have been bothered by various anxiety symptoms in the past week, using a 4-point scale ranging from 1 (not at all) to 4 (severely). The Center for Epidemiologi- 
Table 1.

Descriptive Statistics, Intercorrelations, and Scale Alphas for Study Variables

\begin{tabular}{|c|c|c|c|c|c|c|c|c|c|c|c|c|}
\hline Variable & 1 & 2 & 3 & 4 & 5 & 6 & 7 & 8 & 9 & 10 & 11 & 12 \\
\hline 1. Age & - & & & & & & & & & & & \\
\hline 2. Gender (male) & .04 & - & & & & & & & & & & \\
\hline 3. Mother's education & $n-.06$ & .02 & - & & & & & & & & & \\
\hline 4. State (California) & $-.35 * *$ & $-.17 *$ & $.23^{*}$ & - & & & & & & & & \\
\hline 5. Acculturative status & Is -.09 & -.08 & $.20^{*}$ & $.17 *$ & - & & & & & & & \\
\hline 6. Acculturative stress & $s-.14$ & .09 & -.12 & .16 & -.15 & - & & & & & & \\
\hline 7. Parent support & .01 & $-.22 * *$ & $.18^{*}$ & .01 & .04 & -.06 & - & & & & & \\
\hline 8. Peer support & $-.19 *$ & -.13 & .15 & $.28 * *$ & .15 & -.07 & $.30 * *$ & - & & & & \\
\hline 9. Active coping & .19 & -.06 & .14 & .08 & $.17^{*}$ & -.04 & $.26^{* *}$ & .16 & - & & & \\
\hline 10. Avoidant coping & -.02 & .01 & -.07 & -.06 & -.06 & $.28 * *$ & .08 & -.01 & $-.25 * *$ & - & & \\
\hline 11. Anxiety & .00 & -.10 & -.00 & $.22 * *$ & -.05 & $.17 *$ & .15 & $.22 *$ & .01 & $.36^{* *}$ & - & \\
\hline 12. Depression & -.06 & .04 & .00 & .16 & -.10 & $.33 * *$ & -.01 & .10 & $-.29 * *$ & $.43 * *$ & $.60 * *$ & - \\
\hline$M($ or $\%)$ & 23.05 & $33 \%$ & 2.41 & $45.6 \%$ & 3.24 & 2.14 & 3.02 & 2.98 & 3.45 & 2.11 & 1.44 & 1.32 \\
\hline$S D$ & 3.33 & & 1.56 & & 1.10 & 0.62 & 0.74 & 0.81 & 0.71 & 0.57 & 0.50 & 0.62 \\
\hline Scale alphas & & & & & 0.93 & 0.91 & 0.91 & 0.90 & 0.87 & 0.78 & 0.94 & 0.90 \\
\hline
\end{tabular}

Note. Participant Ns ranged from 134 to 148, depending on the variable.

$* p<.05 . * * p<.01$.

cal Studies Depression Scale (Radloff, 1977) assesses frequency of experiencing 20 depressive symptoms during the past week on a scale ranging from 0 (rarely or none of the time) to 3 (most or all of the time).

\section{Analysis Plan}

The primary analyses consisted of a series of hierarchical multiple regressions for each dependent variable (i.e., anxiety or depression). In each regression, Step 1 included acculturative stress, gender, and control variables. One set of moderators (either parent and peer support or active and avoidant coping) was added in Step 2 , and interactions between acculturative stress and each moderator were added in Step 3. Interactions between gender, acculturative stress, and the moderating factors were added in Step 4, and three-way interactions (Gender $\times$ Acculturative Stress $\times$ Moderators) were added in Step 5. Continuous variables were centered before computing interaction terms to reduce nonessential collinearity in the model (Aiken \& West, 1991).

\section{Results}

Descriptive statistics and intercorrelations of the main study variables appear in Table 1. Higher acculturative stress was associated with higher levels of anxiety and depression. Additionally, peer support was positively associated with anxiety symptoms. Greater use of active coping strategies was associated with fewer depressive symptoms, whereas greater use of avoidant coping strategies was associated with more depressive and anxiety symptoms. Californians reported higher levels of anxiety than Texans did, so state was included as a control variable in the regressions predicting anxiety. The other potential control variables were not significantly associated with the dependent variables and were dropped.

Results of regression analyses predicting the two adjustment outcomes are summarized in Tables 2 and 3. Each table shows the results involving one set of moderators (i.e., parent and peer support, active and avoidant coping). Five steps were tested in each analysis, but only the first four steps are shown in the tables, as Step 5 did not result in increases in $R^{2}$. Only steps resulting in a significant increase in $R^{2}$ are discussed unless otherwise noted.

\section{Regressions Predicting Psychological Functioning From Social Support}

Multivariate results regarding the effects of social support on symptoms of anxiety and depression are shown in Table 2. Turning first to the regressions predicting anxiety symptoms, state was significant in Step 1 (data not shown), so that students from California reported higher levels of anxiety than students from Texas. In Step 3 , the interaction between acculturative stress and social support from parents was significant, as well as the interaction between acculturative stress and support from peers. We conducted simpleslope analyses to examine these interactions (Aiken \& West, 1991). Figure 1 shows the regression lines for students with low parental support (1 standard deviation below the mean) and high parental support (1 standard deviation above the mean). As illustrated, for students with low levels of parental support, increases in acculturative stress were associated with increases in anxiety; however, for those with higher levels of parental support, this relation was not significant. The pattern was similar for peer support (data not shown). Among students reporting low levels of peer support, increases in acculturative stress were associated with higher levels of anxiety symptoms, but this association was not significant for those reporting high levels of peer support.

Regression results for depressive symptoms are also shown in Table 2. In Step 1, acculturative stress was positively and significantly related to depression levels. In Step 3, the interaction between acculturative stress and parent support was significant, although the change in $R^{2}$ was only marginally significant. A simple-slope analysis indicated that, among students with low levels of parent support, increases in acculturative stress were associated with increases in depressive symptoms, but among students with high levels of parental support, the association was not significant. The pattern was similar to that shown for anxiety in Figure 1. 
Table 2

Regressions Predicting Psychological Functioning From Social Support

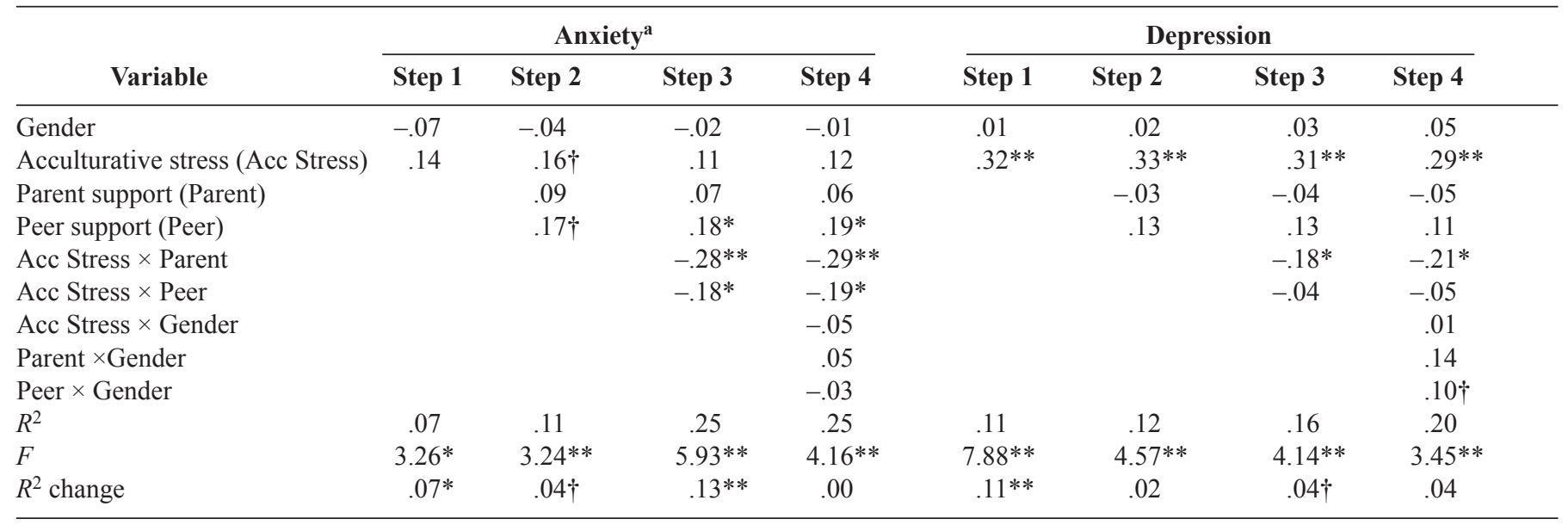

Note. Standardized regression weights are reported. For anxiety and depression models, $N=136$.

${ }^{a}$ Regressions for anxiety controlled for state.

$\dagger p<.10 . \quad * p<.05 . * * p<.01$.

\section{Regression Analyses Predicting Psychological Functioning From Coping}

Regressions examining the effects of coping on symptoms of anxiety and depression are summarized in Table 3. Results for anxiety indicated that higher levels of avoidant coping were associated with higher levels of anxiety (Step 2). In Step 3, the interaction between acculturative stress and active coping was also significant. Simple-slope analyses (Figure 2A) showed that, for students who reported little use of active coping strategies, higher acculturative stress was associated with significantly higher levels of anxiety; however, for those who reported greater use of active coping, higher acculturative stress was associated with significantly fewer anxiety symptoms. In Step 4, the interaction between gender and avoidant coping was significant. For women, greater use of avoidant coping was associated with higher anxiety, whereas for men this relation was nonsignificant. In addition, the interaction between gender and acculturative stress reached significance. In this case, the relation between acculturative stress and anxiety was positive and significant for men but nonsignificant for women.

Turning to depressive symptoms, the coefficients for acculturative stress (Step 1) and active and avoidant coping (Step 2) were each significant, so that higher levels of acculturative stress, lower levels of active coping, and higher levels of avoidant coping were associated with more depressive symptoms (see Table 3 ). The interaction between acculturative stress and active coping was also significant (Step 3). As illustrated in Figure 2B, a simple-slope analysis indicated that higher acculturative stress was associated with more depressive symptoms among students reporting low levels of active coping, but not among students reporting high levels of active coping, consistent with a stress-buffering effect.

\section{Discussion}

Drawing on general models of stress, social support, and coping (e.g., Cohen \& Wills, 1985; Lazarus \& Folkman, 1984), as well as

Table 3

Regressions Predicting Psychological Functioning From Coping

\begin{tabular}{|c|c|c|c|c|c|c|c|c|}
\hline Variable & \multicolumn{3}{|c|}{ Anxiety $^{a}$} & Step 4 & \multicolumn{4}{|c|}{ Depression } \\
\hline Gender & -.08 & -.06 & -.06 & -.06 & .02 & .01 & .02 & .02 \\
\hline Active coping (Active) & & .06 & .07 & .07 & & $-.21 * *$ & $-.21 * *$ & $-.22 * *$ \\
\hline Avoidant Coping (Avoidant) & & $.39 * *$ & $.33 * *$ & $.34 * *$ & & $.32 * *$ & $.28 * *$ & $.29 * *$ \\
\hline Acc Stress $\times$ Active & & & $-.34 * *$ & $-.35 * *$ & & & $-.26^{* *}$ & $-.27 * *$ \\
\hline Acc Stress $\times$ Gender & & & & $.16^{*}$ & & & & $.13 \dagger$ \\
\hline Active $\times$ Gender & & & & -.01 & & & & .11 \\
\hline Avoidant $\times$ Gender & & & & $-.24 * *$ & & & & -.01 \\
\hline$R^{2}$ & .07 & .20 & .28 & .35 & .11 & .29 & .34 & .37 \\
\hline$F$ & $3.30 *$ & $6.63 * *$ & $7.28 * *$ & $6.68 * *$ & $8.50 * *$ & $13.26^{* *}$ & $11.13^{* *}$ & $8.20 * *$ \\
\hline$R^{2}$ change & $.07 *$ & $.13^{* *}$ & $.08 * *$ & $.06 * *$ & $.11 * *$ & $.17 * *$ & $.05 * *$ & .03 \\
\hline
\end{tabular}

Note. Standardized regression weights are reported. For anxiety, $n=137$; for both anxiety and depression, $n=138$.

${ }^{a}$ Regressions for anxiety controlled for state.

$\dagger p<.10 . \quad * p<.05 . \quad * * p<.01$. 


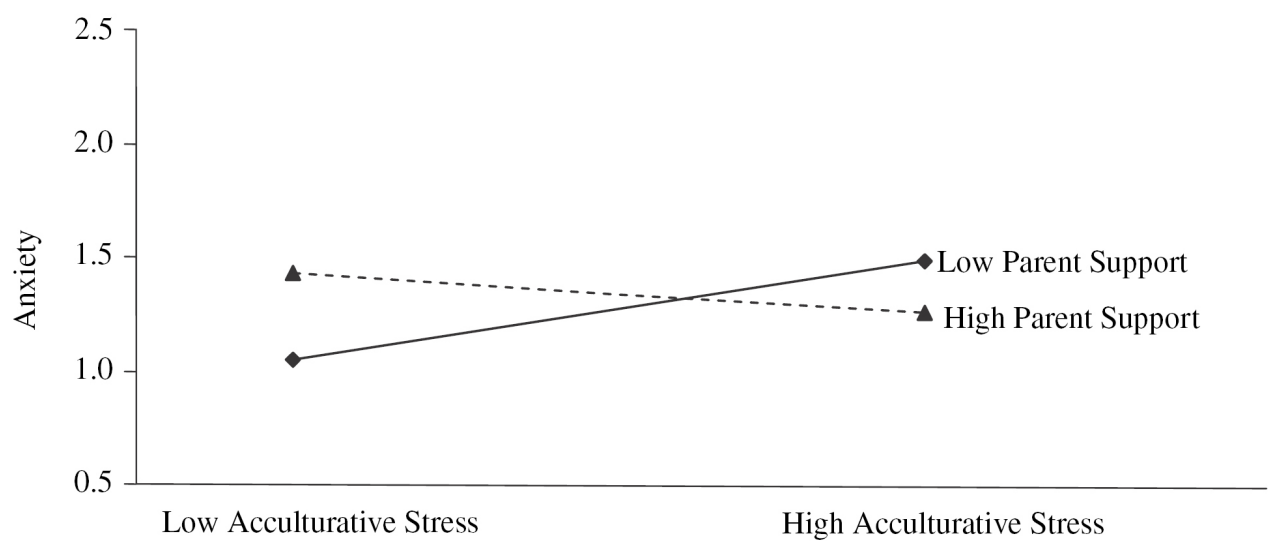

Figure 1. Moderating effect of parent support on the relation between acculturative stress and anxiety.

models of mental health among Latinos (Raffaelli, Carlo, Carranza, and Gonzales-Kruger, 2005; Vega et al., 1985), we examined the association between acculturative stress and psychological functioning among Mexican American college students and assessed the buffering role of social support and coping. The results underscore the detrimental effects of acculturative stress on the psy- chological functioning of Mexican American college students and highlight the protective role of social support from parents and use of active coping strategies. The findings provide insight into resilience among a growing segment of the population known to experience high levels of stress.
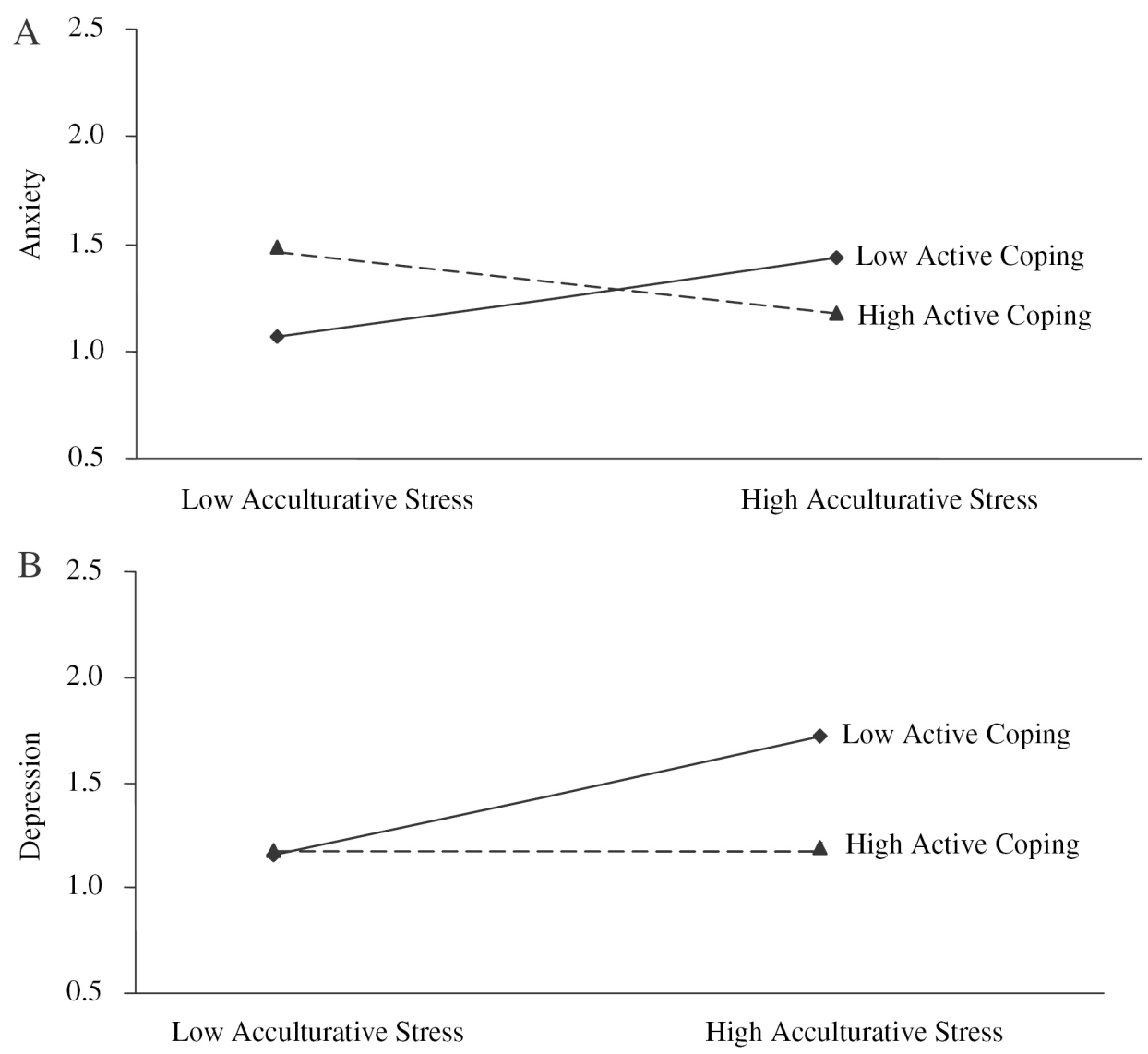

Figure 2. Moderating effect of active coping on the relation between acculturative stress and (a) anxiety and (b) depression. 


\section{Acculturative Stress and Psychological Functioning}

As expected, acculturative stress was associated with poorer psychological functioning among Mexican American college students. Although college populations are assumed to be more acculturated than Latinos in the general population, our results and those from other studies (e.g., Mena et al., 1987; Padilla et al., 1986) indicate that many later generation college students experience this form of stress. In our Mexican American sample, acculturative stress scores were moderate but showed sufficient variability to permit associations with anxiety and depression in the bivariate analyses (although the association with anxiety symptoms was lost in the regressions when we controlled for state). Moreover, the associations appeared to be similar for men and women, as the interaction between gender and acculturative stress was rarely significant. These results are in keeping with the small body of research linking acculturative stress to poorer psychological functioning in Latino samples (e.g., Hovey \& King, 1996; Hovey \& Magaña, 2000; Rodriguez et al., 2000; Salgado de Snyder, 1987). Comparing our findings to those of previous studies indicates that acculturative stress has similar detrimental psychological effects among Mexican American college students as among Latino adolescents and adults.

Whereas most studies of stress among college students have utilized general measures of psychological distress, we assessed specific negative emotional states (i.e., anxiety and depression). The findings for these two variables differed in that the effect of acculturative stress was more robust for depression than for anxiety and some moderating effects were found only for anxiety. These results indicate that a more differentiated picture of the effects of acculturative stress can be obtained by including specific measures of psychological functioning. The distinction between anxiety and depression may prove important for understanding the effects of acculturative stress on academic performance among Latino college students. Research has shown more consistent associations between depression and academic performance than between anxiety and academic performance. For example, depressive symptoms were inversely associated with grade point average in a sample of Latino adolescents (Alva \& de Los Reyes, 1999), and depressive symptoms predicted declines in academic performance among British college students (Andrews \& Wilding, 2004). In contrast, findings on the effects of anxiety are mixed (Alva \& de Los Reyes, 1999; Andrews \& Wilding, 2004; Svanum \& Zody, 2001). The links among acculturative stress, anxiety and depression, and academic performance require further study. However, the available evidence suggests that depression and anxiety may have differential effects on Latino college students' academic performance.

\section{Moderating Effects of Social Support and Coping}

We predicted that social support from parents and peers would moderate the relations between acculturative stress and both anxiety and depression so that higher levels of stress would not result in higher symptom counts for students who reported high levels of social support. The results were largely but not entirely consistent with this hypothesis. As predicted, a detrimental effect of acculturative stress was seen for students who reported low levels of parent (and peer) support but not for those reporting high levels of social support. Moreover, when acculturative stress was high, students who perceived high availability of social support reported fewer symptoms than those who perceived less social support. However, when acculturative stress was low, those who perceived high social support reported more symptoms than their peers with lower levels of social support, a finding not predicted by the stress-buffering hypothesis. Similar results have been found regarding college stress and social support (Solberg \& Villarreal, 1997). In sum, results suggest that, during periods of high stress, students do benefit from the availability of parent and peer support. However, close relationships involve mutual obligations for help and support. Thus, when students are not experiencing much acculturative stress, their friends and family members may expect emotional and instrumental support from them (e.g., cultural brokering), increasing students' negative affect. In future studies, it may be useful to measure the demands that parents and friends place on students, along with the social support they provide, to see whether the balance of demands and support shifts as students' stress levels wax and wane.

The moderating effects of parental support (which appeared for both anxiety and depression) were more consistent than those for peer support (which appeared only for anxiety). In addition, peer support showed an unexpected positive relation with anxiety. Perhaps students who are anxious seek more peer support. Alternatively, support from friends may increase anxiety if friends espouse perspectives that heighten cultural conflicts or other kinds of distress. In general, the effects of support from peers may depend on who the peers are (Schneider \& Ward, 2003) and the quality of support they provide. Such differential effects could be examined in future studies that measure the quality of peer support received and its effectiveness in reducing psychological distress. Taken together, the differing results for peer and parent support highlight the need to distinguish these two sources of support in studies of Latinos (see also Rodriguez et al., 2003). In keeping with the significant role of the family in Latino culture (Marín \& Marín, 1991), our findings indicate that support from parents is more likely than support from peers to buffer the effects of acculturative stress among Latino college students.

The results for coping provide evidence that active coping strategies are protective for Latino college students, consistent with expectations based on the general stress and coping literature (Compas et al., 2001; Lewis \& Frydenberg, 2004) and other studies of Latinos (Gloria et al., 2005). Active coping was associated with lower depression and also moderated the effects of acculturative stress on depression and anxiety. In each case, the detrimental effect of high acculturative stress was weakened or reversed among students who reported more active coping strategies, which is consistent with the stress-buffering hypothesis. However, when acculturative stress was low, students who reported more active coping appeared to report more anxiety symptoms than those with less active coping, a finding not predicted by the stress-buffering hypothesis. It is noteworthy that Gonzales et al. (2001) also reported unanticipated effects of active coping on depression among minority youth. In that case, active coping was associated with lower levels of depression only at low levels of peer and community stress. Evidently, the effects of active coping among minority youth are not fully captured by the stress-buffering model. Perhaps Latino college students with low acculturative stress are exposed to uncontrollable stressors that are not amenable to active coping; future studies should examine this possibility. In contrast to the results for 
active coping, avoidant coping did not show moderating effects. Although avoidant coping was associated with poorer functioning (higher levels of depressive and anxiety symptoms), it neither buffered nor accentuated the effects of acculturative stress.

We expected to find gender differences in buffering effects, given that other researchers have reported gender differences in the effects of social support and coping strategies (e.g., Gonzales et al., 2001; Slavin \& Rainer, 1990). One significant interaction indicated that avoidant coping predicted increased anxiety among women but not men, offering some evidence that avoidant coping is more detrimental for women. Otherwise, the role of social support and coping appeared to be similar for the two genders. It is unclear whether the sparseness of gender effects in the present study is due to our focus on a Latino college sample or to other factors. Replication in other samples of Latino college students is needed.

It should be kept in mind that the data came from three sites in Texas and California and may not be representative of Mexican American college students nationwide. Thus, studies with samples from other geographic regions would extend our understanding of the ways in which acculturative stress, social support, and coping strategies influence psychological functioning in this population. Furthermore, the relatively small sample size may have limited our ability to detect some interaction effects. Additionally, all data were based on self-reports, potentially inflating the relations among study variables, and some constructs (e.g., coping) were measured using abbreviated scales. Finally, causal order could not be addressed in this cross-sectional study. Longitudinal studies would increase our ability to determine temporal relations among stress, social support, coping, and psychological distress and to examine reciprocal effects.

\section{Conclusion}

Despite these limitations, this study provides one of the first tests of the stress-buffering hypothesis focusing on acculturative stress in Latino college students. The results confirm the negative effects of acculturative stress on Mexican American college students and provide evidence that parental social support and active coping help buffer the effects of high levels of acculturative stress. Our findings suggest that interventions with Latino college students may seek to strengthen close family relationships and teach students to use active forms of coping when confronted with high levels of acculturative stress. Such interventions could enhance the psychological adjustment and retention of Latino college students, creating long-term benefits for their academic achievement and psychological well-being.

\section{References}

Aiken, L. S., \& West, S. G. (1991). Multiple regression: Testing and interpreting interactions. Newbury Park, CA: Sage.

Alva, S. A., \& de Los Reyes, R. (1999). Psychosocial stress, internalized symptoms, and the academic achievement of Hispanic adolescents. Journal of Adolescent Research, 14, 343-358.

Alvan, S. L. J., Belgrave, F. Z., \& Zea, M. C. (1996). Stress, social support, and college adjustment among Latino students. Cultural Diversity \& Mental Health, 2, 193-203.

American Council on Education (2005, February, 14). ACE releases its annual status report on minorities in higher education. Washing- ton, DC: Author. Retrieved May 17, 2006, from http://www.acenet. edu/AM/Template.cfm?Section=20052\&TEMPLATE $=/ \mathrm{CM} /$ ContentDisplay.cfm\&CONTENTID $=3701$

Andrews, B., \& Wilding, J. M. (2004). The relation of depression and anxiety to life-stress and achievement in students. British Journal of Psychology, 95, 509-521.

Baca Zinn, M. (1995). Social science theorizing for Latino families in the age of diversity. In R. E.Zambrana (Ed.), Understanding Latino families: Scholarship, policy, and practice (pp. 177-189). Thousand Oaks, CA: Sage.

Barlow, D. H. (2002). Anxiety and its disorders: The nature and treatment of anxiety and panic. New York: Guilford Press.

Beck, A. T., \& Steer, R. A. (1993). Beck Anxiety Inventory. San Antonio, TX: Psychological Corporation.

Carver, C., Scheier, M., \& Weintraub, J. K. (1989). Assessing coping strategies: A theoretically based approach. Journal of Personality and Social Psychology, 56, 267-283.

Cohen, W., \& Wills, T. A. (1985). Social support and the buffering hypothesis. Psychological Bulletin, 98, 310-357.

Compas, B. E., Connor-Smith, J. K., Saltzman, H., Thomsen, A. H., \& Wadsworth, M. E. (2001). Coping with stress during childhood and adolescence: Problems, progress, and potential in theory and research. Psychological Bulletin, 127, 87-127.

Crean, H. F. (2004). Social support, conflict, major life stressors, and adaptive coping strategies in Latino middle school students: An integrative model. Journal of Adolescent Research, 19, 657-676.

Crockett, L. J., Randall, B. A., Shen, Y., Russell, S. T., \& Driscoll, A. K. (2005). Measurement equivalence of the Center for Epidemiological Studies Depression Scale for Latino and Anglo adolescents: A national study. Journal of Consulting and Clinical Psychology, 73, 47-58.

Cuéllar, I., \& Roberts, R. E. (1997). Relations of depression, acculturation, and socioeconomic status in a Latino sample. Hispanic Journal of Behavioral Sciences, 19, 230-238.

Fry, R. (2002). Latinos in higher education: Many enroll, too few graduate. Washington, DC: Pew Hispanic Center. Retrieved November 12, 2006, from http://pewhispanic.org/files/reports/11.pdf

Fuligni, A. J., Tseng, V., \& Lam, M. (1999). Attitudes toward family obligations among American adolescents with Asian, Latin American, and European backgrounds. Child Development, 70, 1030-1044.

Furman, W., \& Buhrmester, D. (1992). Age and sex differences in perceptions of networks of personal relationships. Child Development, 63, 103-115.

Garmezy, N. (1994). Reflections and commentary on risk, resilience, and development. In R. J.Haggerty, L. R.Sherrod, N.Garmezy, \& M.Rutter (Eds.), Stress, risk, and resilience in children and adolescents: Processes, mechanisms, and interventions (pp. 1-18). New York: Cambridge University Press.

Gil, A. G., Vega, W. A., \& Dimas, J. M. (1994). Acculturative stress and personal adjustment among Hispanic adolescent boys. Journal of Community Psychology, 22, 43-54.

Gloria, A. M., Castellanos, J., \& Orozco, V. (2005). Perceived educational barriers, cultural fit, coping responses, and psychological well-being of Latina undergraduates. Hispanic Journal of Behavioral Sciences, 27, 161-183.

Gonzales, N. A., Tein, J., Sandler, I. N., \& Friedman, R. J. (2001). On the limits of coping: Interactions between stress and coping for inner-city adolescents. Journal of Adolescent Research, 16, 372-395.

Hovey, J. D., \& King, C. A. (1996). Acculturative stress, depression, and suicidal ideation among immigrant and second-generation Latino adolescents. Journal of the American Academy of Child \& Adolescent Psychiatry, 35, 1183-1192. 
Hovey, J. D., \& Magaña, C. G. (2002). Exploring the mental health of Mexican migrant farm workers in the Midwest: Psychological predictors of psychological distress and suggestions for prevention and treatment. The Journal of Psychology, 136, 493-513.

Lazarus, R. S., \& Folkman, S. (1984). Stress, appraisal, and coping. New York: Springer.

Lewis, R., \& Frydenberg, E. (2004). Thriving, surviving, or going under: Which coping strategies are related to which outcomes? In E.Frydenberg (Ed.), Thriving, surviving, or going under: Coping with everyday lives (pp. 3-23). Greenwich, CT: Information Age.

Marín, G., \& Marín, B. V. (1991). Research with Hispanic populations. Newbury Park, CA: Sage.

Marín, G., Sabogal, G., Marín, B. V., Otero-Sabogal, R., \& Perez-Stable, E. J. (1987). Development of a short acculturation scale for Hispanics. Hispanic Journal of Behavioral Sciences, 9, 183-205.

Masten, A. S., \& Coatsworth, J. D. (1998). The development of competence in favorable and unfavorable environments: Lessons from research on successful children. American Psychologist, 53, 205-220.

Mena, F. J., Padilla, A. M., \& Maldonado, M. (1987). Acculturative stress and specific coping strategies among immigrant and later generation college students[Special issue]. Hispanic Journal of Behavioral Sciences, 9, 207-225.

Miranda, A. O., Bilot, J. M., Peluso, P. R., Berman, K., \& Van Meek, L. G. (2006). Latino families: The relevance of the connection among acculturation, family dynamics, and health for family counseling research and practice. The Family Journal: Counseling and Therapy for Couples and Families, 14, 268-273.

Padilla, A. M., Alvarez, M., \& Lindholm, K. J. (1986). Generational status and personality factors as predictors of stress in students. Hispanic Journal of Behavioral Sciences, 8, 275-288.

Procidano, M. E., \& Heller, K. (1983). Measures of perceived social support from friends and from family: Three validation studies. American Journal of Community Psychology, 11, 1-24.

Quintana, S. M., Vogel, M. C., \& Ybarra, V. C. (1991). Meta-analysis of Latino students' adjustment in higher education. Hispanic Journal of Behavioral Sciences, 13, 155-168.

Radloff, L. S. (1977). The CES-D scale: A self-report depression scale for research in the general population. Applied Psychological Measurement, 1, 385-401.

Raffaelli, M., Carlo, G., Carranza, M. A., \& Gonzales-Kruger, G. E. (2005). Understanding Latino children and adolescents in the mainstream: Placing culture at the center of developmental models. In R.Larson \& L.Jensen (Eds.), New horizons in developmental research: New directions for child and adolescent development (pp. 23-32). San Francisco: Jossey-Bass.

Roberts, R. E., \& Sobhan, M. (1992). Symptoms of depression in adolescence: A comparison of Anglo, African, and Hispanic Americans. Journal of Community Psychology, 25, 639-651.

Rodriguez, N., Mira, C. B., Myers, H. E., Monis, J. K., \& Cardoza, D. (2003). Family or friends: Who plays a greater supportive role for Latino college students?Cultural Diversity \& Ethnic Minority Psychology, 9, 236-250.

Rodriguez, N., Myers, H. F., Morris, J. K., \& Cardoza, D. (2000). Latino college student adjustment: Does an increased presence offset minority-status and acculturative stresses? Journal of Applied Social Psychology, 30, 1523-1550.

Rogler, L. H., Cortés, D. E., \& Malgady, R. G. (1991). Acculturation and mental health status among Hispanics. American Psychologist, 46, 585-597.
Saldaña, D. H. (1994). Acculturative stress: Minority status and distress. Hispanic Journal of Behavioral Sciences, 16, 116-128.

Salgado de Snyder, V. N. (1987). Factors associated with acculturative stress and depressive symptomatology among married Mexican immigrant women[Special issue]. Psychology of Women Quarterly, $11,475-488$.

Schneider, M. E., \& Ward, D. J. (2003). The role of ethnic identification and perceived social support in Latinos' adjustment to college. Hispanic Journal of Behavioral Sciences, 25, 539-554.

Slavin, L., A., \& Rainer, K. L. (1990). Gender differences in emotional support and depressive symptoms among adolescents: A prospective analysis. American Journal of Community Psychology, 18, 407-421.

Solberg, V. S., Valdez, J., \& Villarreal, P. (1994). Social support, stress, and Hispanic college student adjustment: Test of a diathesis-stress model. Hispanic Journal of Behavioral Sciences, 16, 230-239.

Solberg, V. S., \& Villarreal, P. (1997). Examination of self-efficacy, social support, and stress as predictors of psychological and physical distress among Hispanic college students. Hispanic Journal of Behavioral Sciences, 19, 182-201.

Svanum, S., \& Zody, Z. B. (2001). Psychopathology and college grades. Journal of Counseling Psychology, 48, 72-76.

Szapocznik, J., Scopetta, M. A., Kurtines, W. M., \& Arnalde, M. A. (1978). Theory and measurement of acculturation. Interamerican Journal of Psychology, 12, 113-130.

Torres Stone, R. A., Rivera, F., \& Berdahl, T. (2004). Predictors of depression among non-Hispanic Whites, Mexicans and Puerto Ricans: A look at race/ethnicity as a reflection of social relations. Race and Society, 7, 79-94.

U.S. Department of Health and Human Services (2001). Mental health: Culture, race, and ethnicity. A supplement to Mental Health: A report of the Surgeon General. Rockville, MD: U.S. Department of Health and Human Services, Substance Abuse and Mental Health Services Administration, Center for Mental Health Services.

Varela, R. E., Vernberg, E. M., Sanchez-Sosa, J. J., Riveros, A., Mitchell, M., \& Mashunkashey, J. (2004). Anxiety reporting and culturally associated interpretation biases and cognitive schemas: A comparison of Mexican, Mexican American, and European American families. Journal of Clinical Child and Adolescent Psychology, 33, 237-247.

Vega, W. A., Hough, R. L., \& Miranda, M. R. (1985). Modeling crosscultural research in Hispanic mental health. In W. A.Vega \& M. R.Miranda, (Eds.), Stress \& Hispanic mental health: Relating research to service delivery (pp. 1-29). Rockville, MD: National Institute of Mental Health.

Vega, W. A., Kolody, B., Valle, R., \& Weir, J. (1991). Social networks, social support, and their relationship to depression among immigrant Mexican women. Human Organization, 50, 154-162.

Wilds, D., \& Wilson, R. (1998). Minorities in higher education. 1997-98 sixteenth annual status report. Washington, DC: American Council on Education, Office of Minority Concerns.

Williams, C. L., \& Berry, J. W. (1991). Primary prevention of acculturative stress among refugees: Application of psychological theory and practice. American Psychologist, 46, 632-641.

Zea, M. C., Jarama, L., \& Bianchi, F. T. (1995). Social support and psychosocial competence: Explaining the adaptation to college in ethnically diverse students. American Journal of Community Psychology, 23, 509-531. 